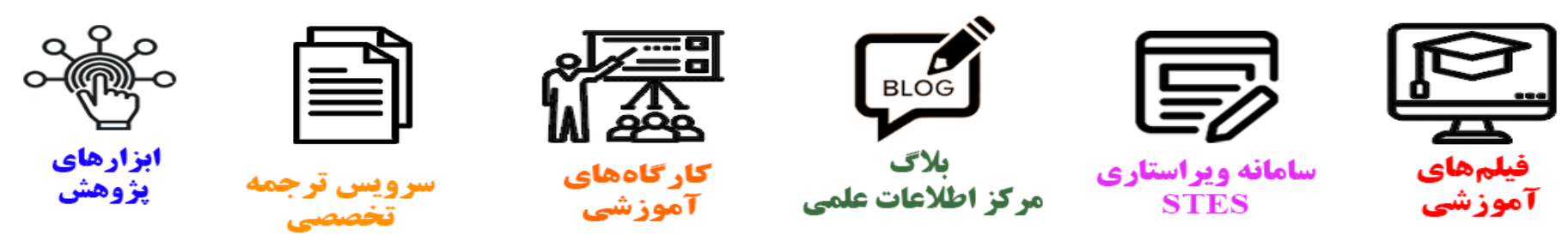

\title{
(c)
}

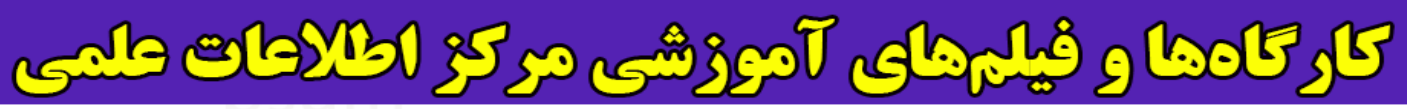
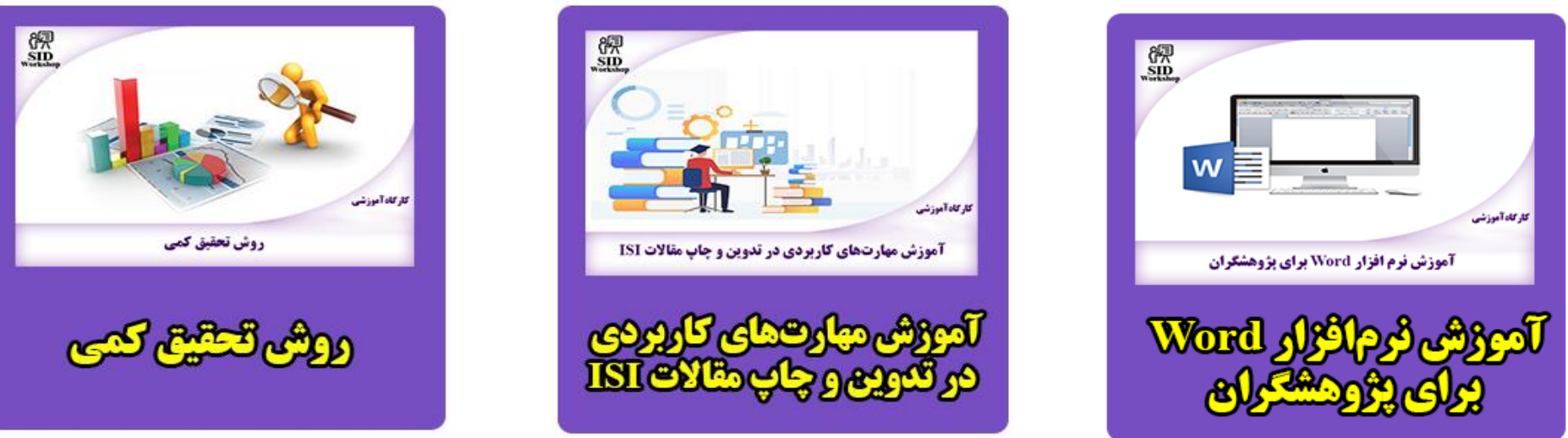


\title{
International Journal of Engineering
}

Journal Hom e page: ww w. ije.ir

\section{The Effect of Various Parameters on Out-of-phase Thermo-mechanical Fatigue Lifetime of A356.0 Cast Aluminum Alloy}

\author{
M. Azadi a,b, G. H. Farrahi*a, G. Winter c, W. Eichlseder c \\ a School of Mechanical Engineering, Sharif University of Technology, Tehran, Iran \\ ${ }^{b}$ Fatigue and Wear Workgroup, Irankhodro Power-train Company (IPCO), Tehran, Iran \\ ${ }^{c}$ Chair of Mechanical Engineering, University of Leoben, Leoben, Austria
}

\section{$P A P E R \quad I N F O$}

Paper history:

Received 14 March 2013

Received in revised form 10 May 2013

Accepted 16 May 2013

\section{Keywords:}

Thermo-mechanical Fatigue

A356.0 Aluminum Alloy

Dwell Time

Maximum Temperature

Cyclic Softening

\section{$A B S T T R A C T$}

In this paper, the effect of various parameters on the out-of-phase thermo-mechanical fatigue (OPTMF) lifetime of the A356.0 cast aluminum alloy is investigated. Studied parameters include the maximum temperature, the dwell time, and the thermo-mechanical loading factor. OP-TMF tests are conducted considering realistic running conditions of diesel engine cylinder heads. The maximum temperature varies between 200 to $275^{\circ} \mathrm{C}$ and the thermo-mechanical loading factor, which is the ratio of the mechanical strain to the thermal strain, is considered between 75 to $150 \%$. The dwell time (or the holding time) changes between 5 to $180 \mathrm{sec}$. at the maximum temperature. Fracture surfaces of specimens are studied using the scanning electron microscopy (SEM). These SEM images reveal that the A356.0 alloy has a ductile behavior. The cyclic softening phenomenon is also observed during stress-strain hysteresis loops. TMF test results demonstrate that the dwell time bears no significant effect upon the lifetime. However, large influences for the maximum temperature and the thermomechanical loading factor are depicted in the lifetime of the A356.0 alloy.

\section{INTRODUCTION}

Cast aluminum-silicon-magnesium alloys such as A356.0 (AlSi7Mg0.3) alloy are widely used in diesel engine cylinder heads due to their relatively high strength to weight ratio, low cost, and provision of affordable improvements in the fuel efficiency. Cylinder heads, during the start-stop operation, are subjected to thermal and mechanical cyclic loadings. Therefore, the thermo-mechanical fatigue behavior becomes a major concern of automotive industries with regard to the components integrity and their reliability [1-3]. These out-of-phase (OP) loading conditions in cylinder heads, have several important parameters such as the temperature range (consequently thermal loads due to the combustion), the dwell time (holding the temperature during a specific time), and mechanical loads (due to bolts tightening). Herein, a thermomechanical loading factor can be defined as a ratio of

*Corresponding Author Email: farrahi@sharif.edu (G.H. Farrahi) the mechanical strain to the thermal strain which is constant during a test.

Many researchers have been working on the fatigue behavior of aluminum alloys. Several scientists have investigated the high cycle fatigue (HCF) behavior [413] and the low cycle fatigue (LCF) behavior [14-16] of aluminum alloys in both room and high temperatures. However, fewer articles have been presented in the field of thermo-mechanical fatigue (TMF) loadings. Moridi et al. [2-3] investigated the TMF behavior of A356.0 alloy with a thermal barrier coating. In their finite element simulation, they considered effects of the thickness and the roughness of the coating system. As another example, the microstructure modeling for the high temperature cyclic behavior of A319-T6 alloy was carried out by Sehitoglu et al. [17, 18].

Beck et al. [19] performed various TMF tests on two aluminum alloys (AlSi10Mg0.3 and AlSi10Mg0.6), unreinforced and reinforced, with \%15 volume discontinuous $\mathrm{Al}_{2} \mathrm{O}_{3}$ (Saffil) fibers. TMF and superimposed $\mathrm{TMF} / \mathrm{HCF}$ behaviors of $\mathrm{Al}-\mathrm{Si} 7-\mathrm{Mg} 0.3$ cast alloy were also investigated [20, 21]. By 
metallographic investigations and scanning electron microscopy (SEM) studies, it was found that crack initiation generally took place at the interface between eutectic Si particles and the $\alpha$-Al matrix [20-21]. In another article, Beck et al. [22] studied the fatigue behavior of AlSi6Cu4 alloy under out-of-phase (OP) TMF loadings which were superimposed by $\mathrm{HCF}$ loadings. Results illustrated that at $300^{\circ} \mathrm{C}$ of the maximum temperature, the TMF lifetime was measured at about 2000 at $180 \mathrm{sec}$. of the dwell time. When the dwell time was eliminated, the TMF lifetime increased to 3000 cycles. At $250^{\circ} \mathrm{C}$ of the maximum temperature, this increase in the lifetime was almost doubled.

Thomas et al. [23, 24] presented fatigue lifetime prediction models based on energy and classical approaches, such as the Smith-Watson-Topper (SWT) criterion for A356.0 alloy under TMF/LCF loadings. The effect of different casting processes on isothermal (in room and high temperatures) and un-isothermal fatigue behaviors of aluminum-silicon alloys was studied by Bose-Filho et al. [25]. A modified energy criterion, entitled "unified energy approach" was proposed by Riedler et al. [26, 27] who compared their model (which was calibrated with TMF test results) to conventional approaches for $\mathrm{AlSi} 7 \mathrm{MgCu} 0.5$ alloy. Takahashi and Sasaki [28] checked the effect of the artificial ageing process on the TMF lifetime of A356T6 alloy. The ageing time was found to be very effective for the rate of changes in the loop-end stress amplitude. This change rate could be expressed as a state of the stress relaxation. There also existed a good correlation (a reverse relation) between the change rate and the fatigue lifetime. A fatigue lifetime comparison of two lost foam cast aluminum-silicon alloys (A319 and A356 alloys) was performed by Tabibian et al. [29] under TMF conditions. Grieb et al. [30] performed different TMF tests on cast aluminum alloys using a near-component-similar sample (such as a valve bridge on the combustion chamber in cylinder heads) and derived an ageing model from experimental results.

According to the literature review, several research works have studied the temperature effect on the TMF behavior of materials. However, the behavior of A356.0 alloy under OP-TMF loadings, and for the cylinder heads application, also effects of the dwell time within the range of zero to $180 \mathrm{sec}$. on the stress relaxation and the thermo-mechanical loading factor have not been studied yet. Distinguishing between the fatigue number of cycles and the fatigue lifetime is important. Therefore, it is considered as a part of this particular research of the dwell time effect.

Effects of the dwell time, the maximum temperature, and the thermo-mechanical loading factor on the TMF lifetime of A356.0 alloy are studied in this work. Results of OP-TMF experiments, similar to real loading conditions of the cylinder heads operation, and the influence of mentioned parameters are presented.
Fracture surfaces of specimens are also investigated by SEM images. In addition, fatigue lifetime prediction lines are presented for each TMF loading parameter.

\section{EXPERIMENTAL DETAILS}

The material in the present investigation is a cast aluminum-silicon-magnesium alloy (A356.0). This alloy is widely used in diesel engine cylinder heads. The chemical composition of the A356.0 alloy is measured as $7.06 \% \mathrm{Si}, 0.37 \% \mathrm{Mg}, 0.15 \% \mathrm{Fe}, 0.01 \% \mathrm{Cu}, 0.02 \%$ $\mathrm{Mn}, 0.13 \% \mathrm{Ti}$ and $\mathrm{Al}$ balance. The production method is a permanent mold gravity casting process. The microstructure of the A356.0 alloy before TMF tests (shown in Figure 1) consists of $\mathrm{Al}$ dendrites and the $\mathrm{Si}$ particles phase. The second dendrite arm spacing is measured as 31.9 micron (the average of several measurements).

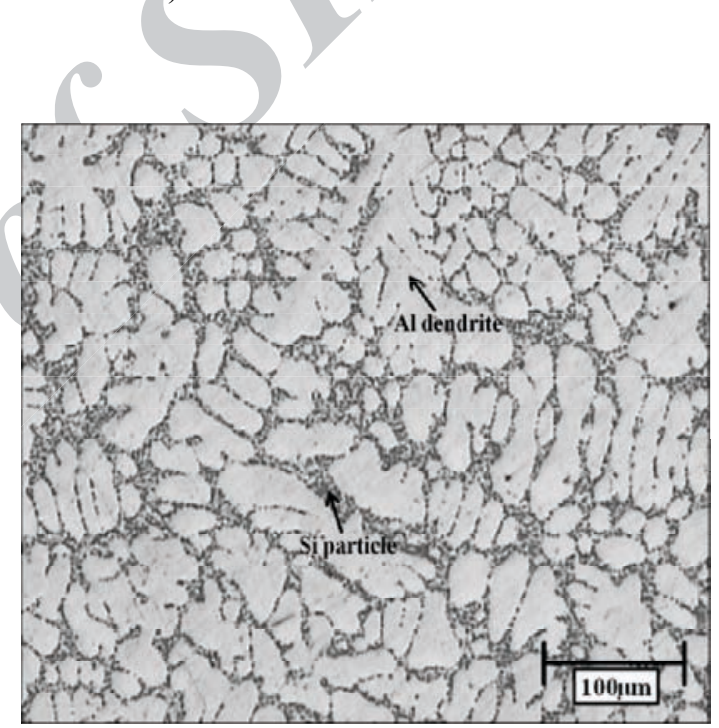

Figure 1. The microstructure of the A356.0 alloy before TMF tests

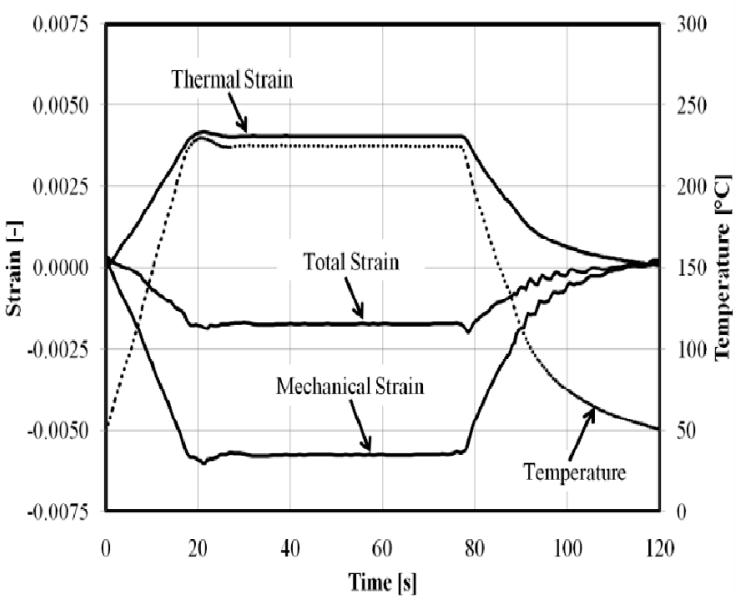

Figure 2. The out-of-phase condition in TMF tests 


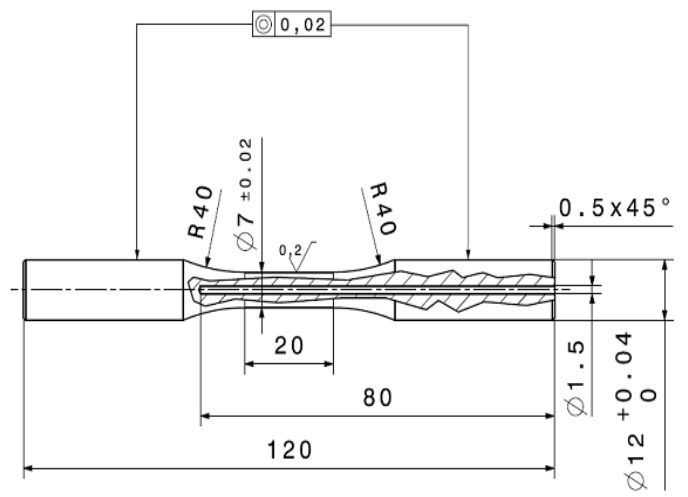

Figure 3. The specimen geometry and its details (dimensions in $\mathrm{mm}$ )

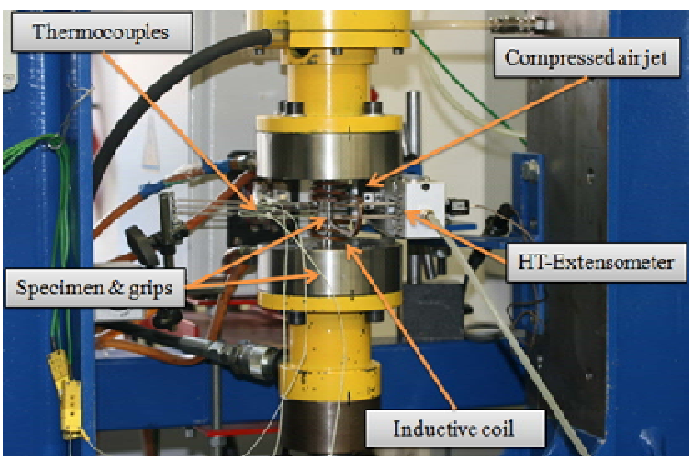

(a)

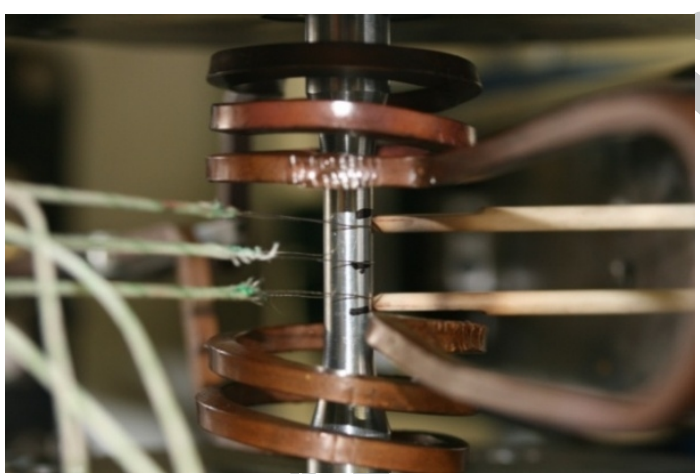

(b)

Figure 4. Fatigue testing equipments for TMF loadings including (a) a general view and (b) the gauge length of the specimen

In the OP-TMF test, the temperature reaches its maximum value, when the strain has a maximum compressive value and vice-versa. This condition is comparable to real loadings in cylinder heads. The outof-phase loading condition in the TMF tests and details of the specimen are shown in Figures 2 and 3, respectively. As it can be seen, a hole of 1.5 millimeters diameter in the center of the specimen is drilled in order to measure and control the temperature. The temperature is measured by a K-type sheath thermocouple in the center of the specimen. Three other K-type thermocouples are used to measure the surface temperature of the specimen within the gauge length.

The stress is calculated during the test by the load over the cross section area of the specimen. The diameter of the specimen is measured before the test within the gauge length. The axial load is measured by a load cell and the strain is measured by a high temperature extensometer. Specimens are heated by an induction system where the temperature reaches its maximum value and remains constant during a dwell time. The cooling system is performed using a compressed air jet. Figure 4 demonstrates fatigue testing equipments. Tests are performed under strain-controlled tension-compression loadings. The heating/cooling rate is constant as $10^{\circ} \mathrm{C} / \mathrm{s}$ for all tests. As an initial condition, TMF tests begin with $0.03 \%$ initial strain. This condition can be compared to initial loadings in cylinder heads due to bolts forces and valve seat insert effects. In TMF tests, the temperature varies between two minimum and maximum values. These tests start at $50^{\circ} \mathrm{C}$ of the minimum temperature $\left(T_{\min }\right)$ which is similar for all tests. The maximum temperature $\left(T_{\max }\right)$ changes at 200 to $275^{\circ} \mathrm{C}$ due to the operation conditions of cylinder heads [29]. Dwell times $\left(t_{D}\right)$ are considered as 5 to $180 \mathrm{sec}$. at the maximum temperature. The thermo-mechanical loading factor $\left(K_{T M}\right)$, defined by Equation (1), is a ratio of the mechanical strain amplitude $\left(\varepsilon_{a, \text { mech }}\right)$ to the thermal strain amplitude $\left(\varepsilon_{a, t h}\right)$. This factor represents the constraint of the system.

$$
\begin{aligned}
K_{T M} & =\frac{\varepsilon_{a, \text { mech }}}{\varepsilon_{a, t h}} \\
K_{T M} & =\frac{\varepsilon_{\text {mech }}\left(T_{\text {max }}\right)-\varepsilon_{\text {mech }}\left(T_{\text {min }}\right)}{\alpha_{\text {th }}\left(T_{\max }-T_{\text {min }}\right)}
\end{aligned}
$$

where, $\alpha_{t h}$ is the thermal expansion coefficient. The thermo-mechanical loading factor varies between 75 to $150 \%$ from test to test and remains constant during every TMF test [27]. Table 1 depicts the TMF tests configuration including loading parameters.

TABLE 1. The TMF tests configuration on the A356.0 alloy

\begin{tabular}{lcccc}
\hline & \multicolumn{4}{c}{$\mathbf{K}_{\mathrm{TM}}(\%)$} \\
\cline { 2 - 5 } $\mathbf{T}_{\min }-\mathbf{T}_{\max }\left({ }^{\circ} \mathrm{C}\right)$ & $\mathbf{7 5}$ & $\mathbf{1 0 0}$ & $\mathbf{1 2 5}$ & $\mathbf{1 5 0}$ \\
\hline $\mathbf{5 0 - 2 0 0}$ & & & $\mathrm{X}$ & \\
$\mathbf{5 0 - 2 2 5}$ & & & $\mathrm{X}$ & $\mathrm{X}^{*}$ \\
$\mathbf{5 0 - 2 5 0}$ & $\mathrm{X}$ & $\mathrm{X}$ & $\mathrm{X}$ & $\mathrm{X}$ \\
$\mathbf{5 0 - 2 7 5}$ & & & $\mathrm{X}$ & \\
\hline
\end{tabular}

* Dwell times are considered as 5, 30, 60 and $180 \mathrm{sec}$. for this case. In all other tests, the dwell time is $5 \mathrm{sec}$. at the maximum temperature. 


\section{RESULTS AND DISCUSSIONS}

\section{1. General Obsevations}

Stress and strain evolutions versus the fatigue life cycles, for a typical TMF test are shown in Figures 5. The stress history includes maximum, minimum, mean and amplitude values. The strain includes total mechanical strain and plastic strain amplitudes. For this test, the thermomechanical loading factor is $150 \%$ and the maximum temperature is $250^{\circ} \mathrm{C}$.

It is worth noting that the plastic strain shown in Figure 5(b) is calculated by the hysteresis loop at zero mean stress line. In addition, the final lifetime of the TMF specimen is defined as a first drop in the maximum stress history during the fatigue life cycles. As demonstrated in Figure 5(a), the stress amplitude decreases during cycles. This behavior shows a cyclic softening for the A356.0 alloy under OP-TMF loadings. Further evidence is that the plastic strain increases during cycles as shown in Figure 5(b). Herein, the total strain amplitude is constant during cycles according to strain-controlled test conditions. This cyclic softening behavior of aluminum alloys was also reported by Beck et al. [19] as they depicted that the rate of the cyclic softening increases when the maximum temperature increases [19].

Stress-strain and stress-temperature hysteresis loops at various fatigue life cycles during a TMF test are demonstrated in Figure 6. In this test, the maximum temperature is $225^{\circ} \mathrm{C}$ and the dwell time is $60 \mathrm{sec}$. at the maximum temperature. The increase in the plastic strain can be observed during the fatigue life cycles. Therefore, it can be concluded that the cyclic softening behavior happens in the A356.0 alloy. According to the literature $[31,32]$, when the ratio of the ultimate tensile strength to the $0.2 \%$ offset yield strength is greater than 1.4 , the cyclic hardening will occur.

Furthermore, if this ratio is smaller than 1.2, the cyclic softening will occur. Within the mentioned range (1.2 to 1.4) of this ratio, it is difficult to say which behavior occurs in the material. It should be mentioned that this ratio is calculated as 1.1 for the A356.0 alloy according to tensile test results at high temperatures (from 150 to $250^{\circ} \mathrm{C}$ ). Therefore, this value proves the cyclic softening behavior for aluminum alloys.

The amount of softening $(A S)$ which is incurred during fatigue life cycles is calculated with respect to the stress value of the first cycle [33], as given in Equation (2).

$$
A S(\%)=\frac{\sigma_{\text {mid }- \text { life }}-\sigma_{\text {initial }}}{\sigma_{\text {initial }}} \times 100
$$

where, $\sigma_{\text {initial }}$ and $\sigma_{\text {mid-life }}$ denote the peak tensile stress at the first cycle and at the mid-life cycle, respectively. Then, the amount of softening can be calculated.

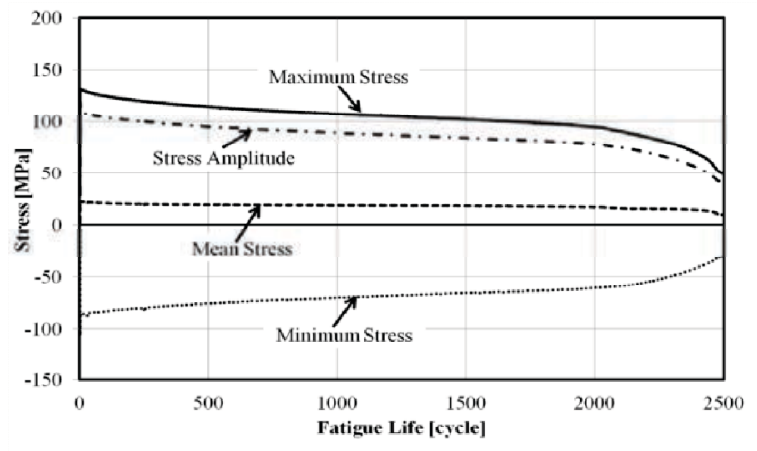

(a)

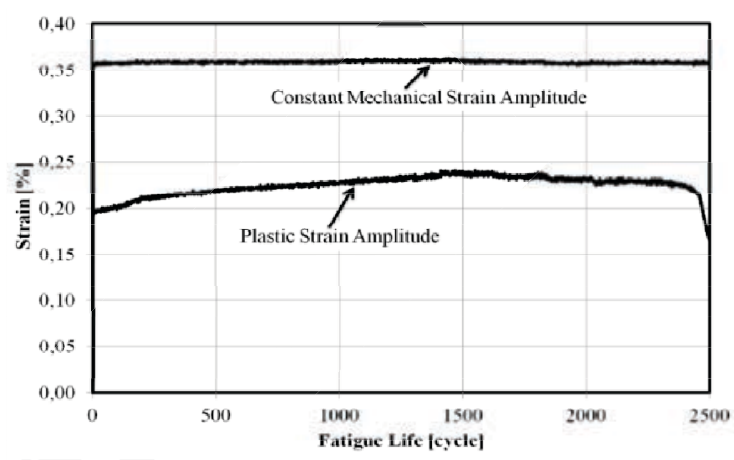

(b)

Figure 5. TMF test results including (a) stress and (b) strain histories versus the fatigue lifetime

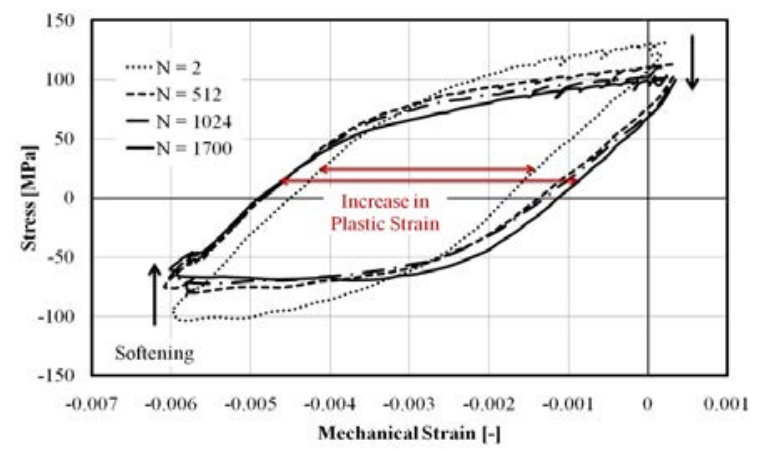

(a)

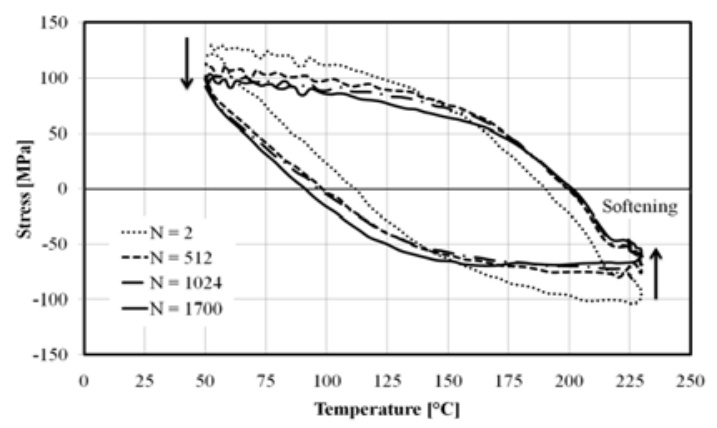

(b)

Figure 6. TMF test results including (a) stress-strain and (b) stress-temperature hysteresis loops at different fatigue life cycles 
TABLE 2. The amount of softening in TMF tests at various dwell times

\begin{tabular}{cccc}
\hline $\mathbf{t}_{\mathbf{D}}(\mathbf{s e c})$ at $\mathbf{T}_{\max }$ & $\boldsymbol{\sigma}_{\text {initial }}(\mathbf{M P a})$ & $\boldsymbol{\sigma}_{\text {mid-life }}(\mathbf{M P a})$ & $\mathbf{A S}(\mathbf{\%})$ \\
\hline 5 & 139.03 & 118.43 & 14.82 \\
30 & 146.40 & 109.30 & 25.34 \\
60 & 134.92 & 107.20 & 20.55 \\
180 & 138.06 & 84.84 & 38.55 \\
\hline
\end{tabular}

Table 2 shows these calculations for 50 to $250^{\circ} \mathrm{C}$ of the temperature range and $125 \%$ of the thermomechanical loading factor. As demonstrated in Table 2, by increasing the dwell time, the stress (at the mid-life cycle) decreases and consequently, the amount of softening increases. It can be noted that this increasing behavior of softening in the A356.0 alloy is almost linear as a function of the dwell time.

Shankar et al. [33] reported about $24 \%$ of this amount for a modified 9Cr-1Mo ferritic steel under OPTMF loadings due to the micro-structural evolution during cycling. In addition, they illustrated that the softening rate was independent of the external environment during testing and was due to the annihilation and the rearrangement of dislocations [33]. For the comparison, the amount of softening is between 15 to $39 \%$ for the A356.0 alloy under OP-TMF loadings. This phenomenon can occur due to microstructural changes in the material where the stress at the mid-life cycle decreases (due to higher stress relaxation) with the increase of the dwell time [22].

Micro-structural changes include an ageing phenomenon. The material will be aged at high temperatures. After ageing, silicon particles become more spherical and finer along primary aluminum grains and several inter-metallic phases start to dissolve in the matrix [34]. It is known that micro-cracks initiate at the early stage of the TMF test. Then, during the fatigue cycling, cracks grow transforming to macro-cracks. In aluminum alloys, a crack usually initiates at a eutectic Si particle which is detached from the surrounding $\alpha-\mathrm{Al}$ matrix. Then, micro-cracks solely propagate along the eutectic regions [20-22]. The crack initiation at detached Si particles is caused by the thermal and mechanical misfit of these brittle Si particles in comparison to the surrounding ductile matrix. The crack propagation is characterized by the connection of such micro-cracks in eutectic regions of the microstructure. Therefore, during the fatigue cycling, these micro-cracks change to macrocracks [22]. SEM Images of the TMF specimen are demonstrated in Figures 7 to 10. These pictures show the cracks, micro-coalescence (dimples) and porosities on the fracture surface. Figure 7 shows three porosities which are placed near surface edges (P.No.1, P.No.2 and P.No.3). The first and the third ones are shrinkage porosities which are made during the casting process. The second one is on the surface edge of the central hole (P.No.2) which include a crack. In strain-controlled tension-compression tests, the stress is uniform and constant at the cross section area of the specimen. Thus, cracks can initiate where ever in the specimen. In these tests, the roughness has no major effects on the crack initiation in such rotary bending fatigue tests where the stress value becomes maximum at the outer surface of the specimen. Here, casting porosities as high energy regions have an important role in cracking. On a wide area of the fracture surface in Figure 7, the ductile fracture can be observed. A small area shows the brittle fracture feature due to the sudden rapture at the last stage of the TMF test. This sudden rupture occurs at the end of the failure when the area reduces (due to cracks propagations) and therefore, the stress increases. During the TMF test, a large plastic deformation happens (as shown in Figure 5). This can be an evidence for ductile fracture regions. Figure 8 shows dimples feature at areas near the P.No.1 position. Figures 9 and 10 demonstrate other porosities. In general, the cyclic deformation and the crack initiation are mainly governed by the TMF cycle which induces large plastic deformations [22].

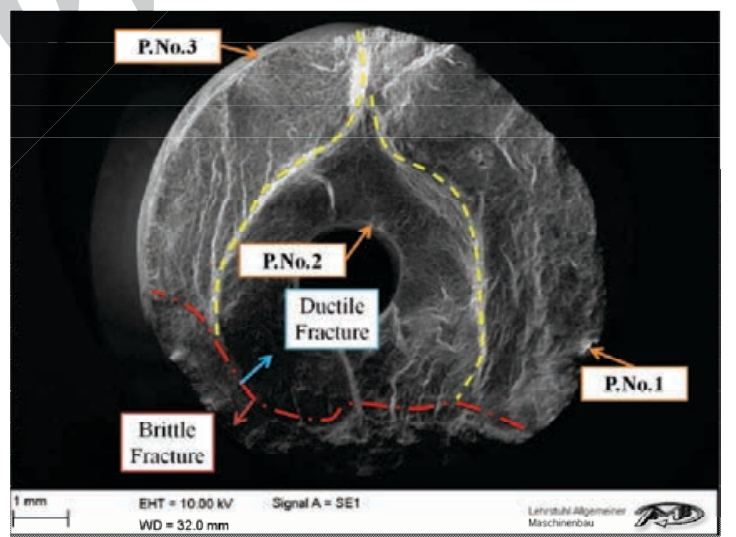

Figure 7. The SEM image for the fracture surface of the TMF specimen

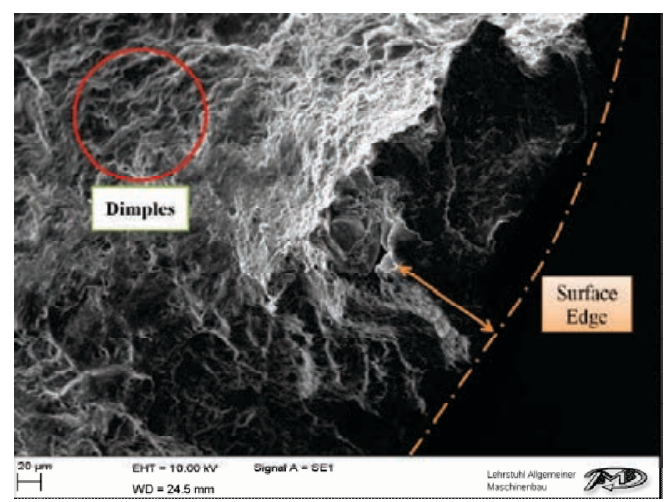

(a) 


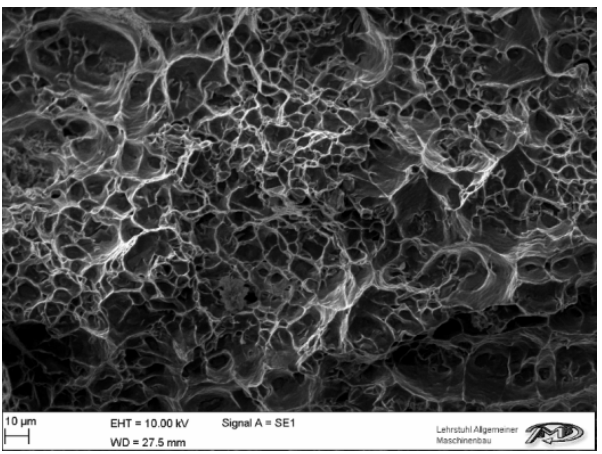

(b)

Figure 8. SEM images including (a) the P.No.1 position and (b) dimples near this area

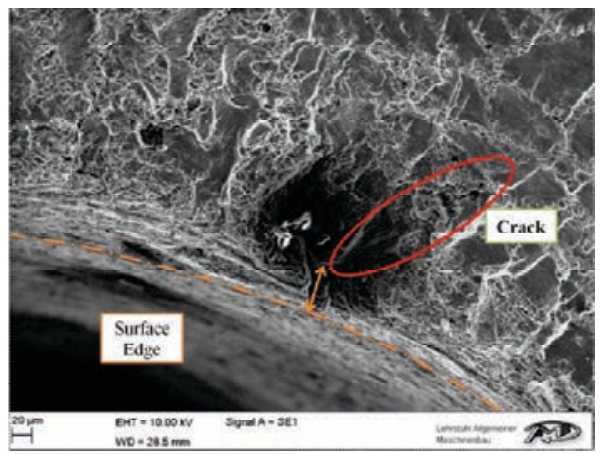

(a)

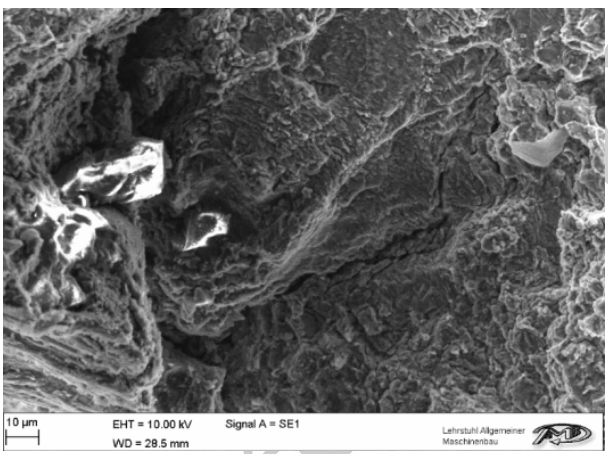

(b)

Figure 9. SEM images including (a) the P.No.2 position and (b) a crack near this area

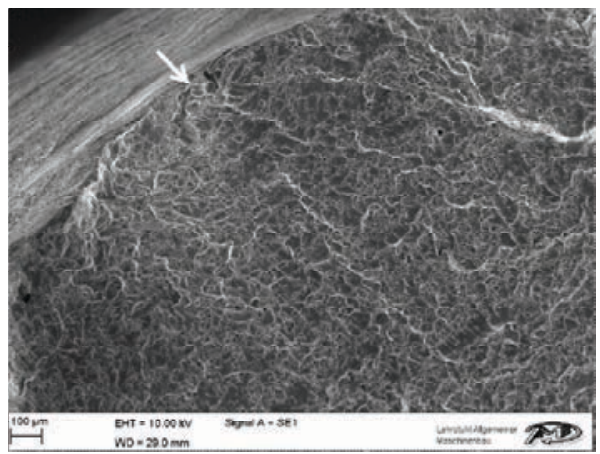

(a)

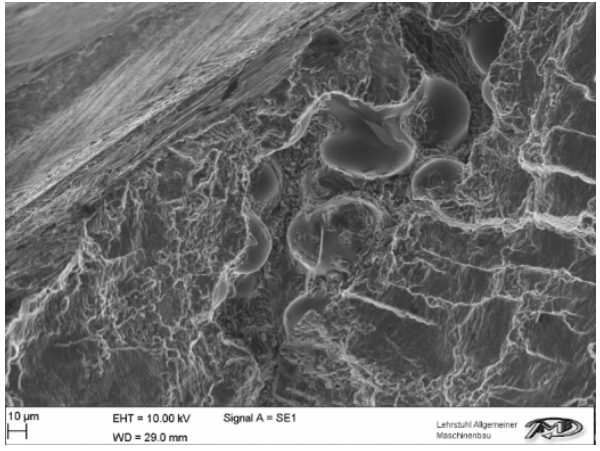

(b)

Figure 10. SEM images of the P.No.3 position on the specimen surface at two different magnifications

3.2. The Effect of the Maximum Temperature When the maximum temperature increases, the plastic strain range will increase due to micro-structural changes, such as ageing effects in the material. The ageing behavior dominates the cyclic deformations under TMF loadings [27]. This will lead to a reduction in the strength and consequently decreases the TMF lifetime [20].

In Figure 11, the stress-temperature hysteresis loop at the mid-life cycle is illustrated. The influence of the temperature on the TMF lifetime is shown in Figure 12 at various maximum temperatures. It should be mentioned that other parameters, such as the dwell time and the thermo-mechanical loading factor, are constant in these tests.

As depicted in Figure 11, when the maximum temperature increases, the stress range decreases due to the cyclic softening behavior and also the temperature dependency of material properties. This reduction in the stress is more significant at the compression state where the temperature reaches its maximum value under outof-phase loadings.

Figure 11 shows that the maximum stress and the mean stress decrease when the maximum temperature increases, as also reported by Luft et al. [20]. The studied material was the same as used in this article but had a heat treatment which leads to lower ductility. In their study, they indicated that the creep phenomenon had a strong influence on this deformation process [20].

As shown in Figure 12, by increasing the maximum temperature, the plastic strain also increases. Therefore, the TMF lifetime decreases with a power function (with $97.6 \%$ coefficient of determination for the fitness). It means that at higher maximum temperatures, the TMF lifetime decreases sharply due to the temperature dependency of material properties. Larger loss occurs in the strength of the material at higher temperatures.

The results of tensile tests at different temperatures ( 25 to $250^{\circ} \mathrm{C}$ ) which are performed on the A356.0 alloy can prove this assertion. The ultimate stress changes between 192 to $95 \mathrm{MPa}$ and the yield stress decreases 
from 138 to $90 \mathrm{MPa}$ within the mentioned temperature range. In addition, the ductility of the material increases up to $150^{\circ} \mathrm{C}$ and then decreases. As presented by Riedler et al. [27], when temperature dependent ageing effects reduce the stress, the plastic strain will raise.

\section{3. The Effect of the Thermo-mechanical} Loading Factor As previously mentioned, the mechanical strain to thermal strain ratio is defined as the thermo-mechanical loading factor $\left(K_{T M}\right)$. The stressstrain hysteresis loop containing the stress versus mechanical and thermal strains is depicted in Figure 13. In Figure 14, the effect of this factor on the TMF lifetime is illustrated. Other parameters (the dwell time and the maximum temperature) are constant in these experiments. By increasing this factor at a constant temperature range, the mechanical strain amplitude increases. The reason is that when the temperature range is considered a same value for all these tests (when used to study the influence of the thermo-mechanical loading factor). Consequently, thermal strains (the product of the temperature range and the thermal expansion coefficient) also become the same value, as it can be observed in Figure 13.

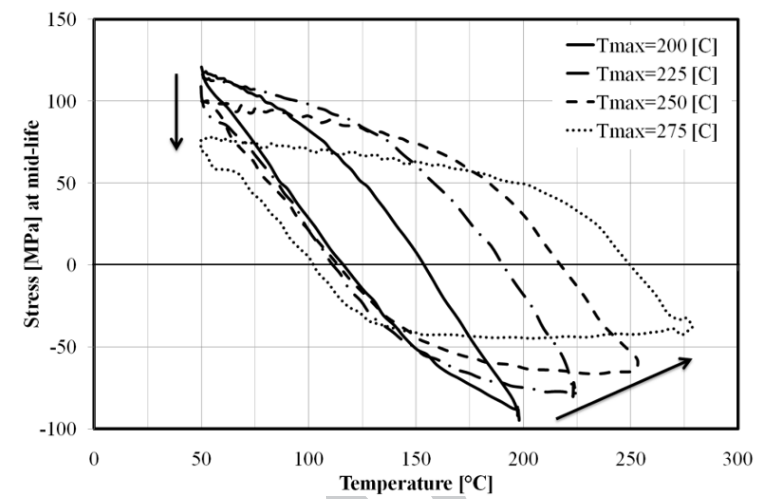

Figure 11. The stress-temperature hysteresis loop for different maximum temperatures

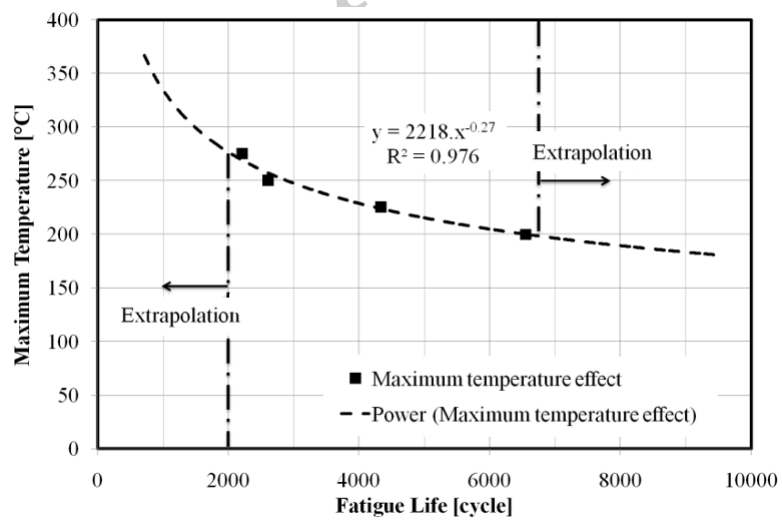

Figure 12. The effect of the maximum temperature on the TMF lifetime of the A356.0 alloy

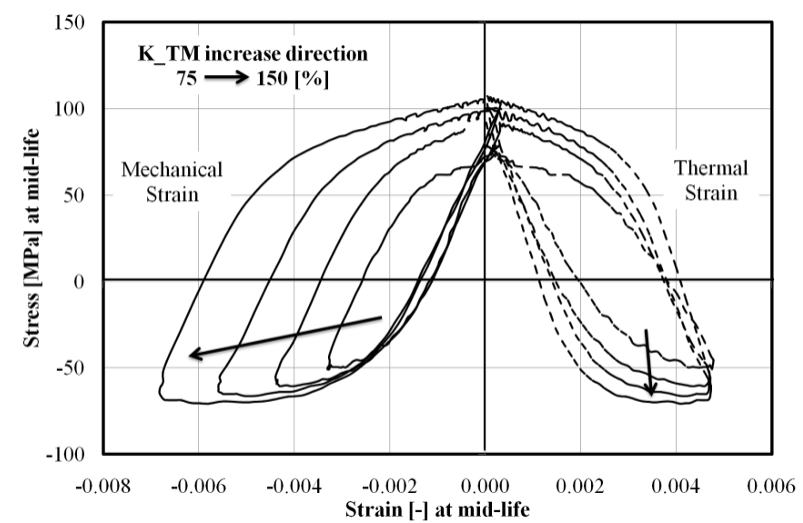

Figure 13. The stress-strain hysteresis loop at different thermo-mechanical loading factors

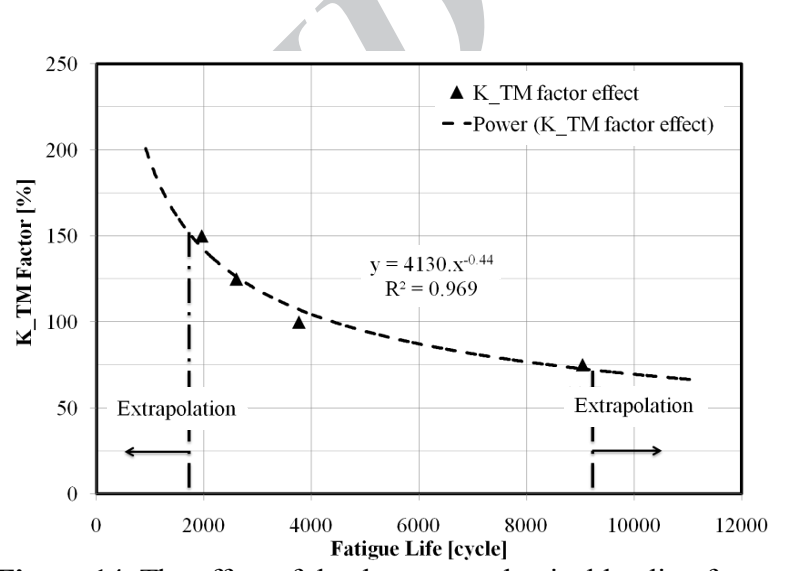

Figure 14. The effect of the thermo-mechanical loading factor on the TMF lifetime of the A356.0 alloy

Therefore, an increase in the thermo-mechanical loading factor leads to an increase in the mechanical strain amplitude based on the definition and due to its constant value in a test. Stress-strain hysteresis loops become bigger for higher thermo-mechanical loading factors (Figure 13).

As anticipated in Figure 14, the TMF lifetime decreases by increasing the thermo-mechanical loading factor (or the mechanical strain amplitude) with a power function (with $96.9 \%$ coefficient of determination for the fitness). Riedler et al. [27] presented this effect on the TMF lifetime for $\mathrm{AlCuBiPb}$ aluminum wrought alloy showing that higher thermo-mechanical loading factors lead to lower cycles to the failure as the loading is higher [27]. This factor for a diesel engine cylinder head was calculated as 50 to $80 \%$ which described the local constraining in real loading conditions [27].

As another result, the reduction in the fatigue lifetime due to this factor effect is more than the reduction due to the maximum temperature effect. It means that the TMF lifetime of A356.0 alloy is more sensitive to the strain. 
3. 4. The Effect of the Dwell Time As expected, increasing the dwell time at the maximum temperature will decrease the TMF lifetime [21]. This is due to the creep mechanism and also the stress relaxation, only at a short time after the material temperature reaches its maximum value. When the dwell time increases, additional plastic deformations are induced due to the stress relaxation [21]. However, it is important to distinguish between the fatigue lifetime (in sec.) and the fatigue number of cycles.

Figure 15 demonstrates the fatigue life cycle of the A356.0 alloy under various dwell times. These tests are performed at $225^{\circ} \mathrm{C}$ of the maximum temperature and $150 \%$ of the thermo-mechanical loading factor. By increasing the dwell time, the fatigue life cycle increases smoothly and linearly in logarithmic scales. It means that, in TMF tests, no significant difference in the fatigue life cycle can be observed under various dwell times. However, the fatigue lifetime (in sec.) increases with a power function of the dwell time. Such a behavior can be explained by high plasticity and the stress relaxation which remains nearly constant under various dwell times, 5, 30, 60 and $180 \mathrm{sec}$. [28].

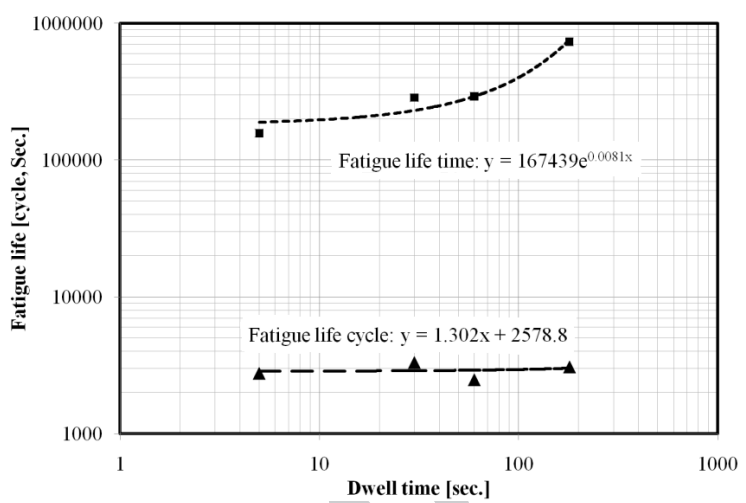

Figure 15. The effect of the dwell time on the TMF life cycle and time of the A356.0 alloy

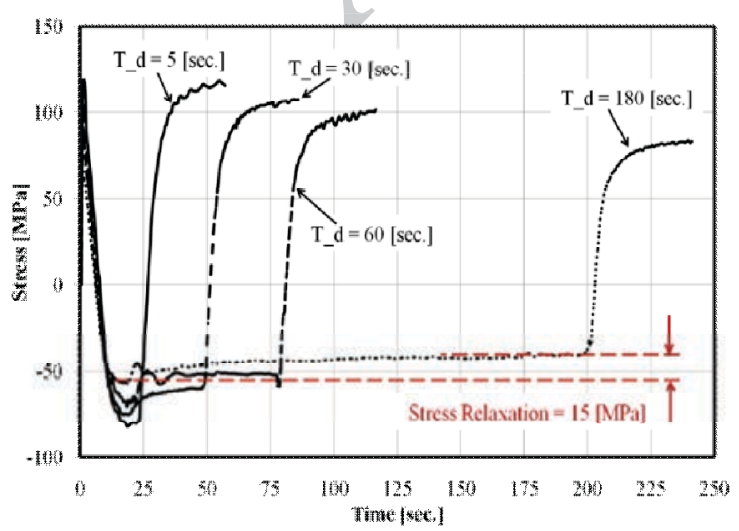

Figure 16. The stress relaxation at the mid-life cycle in OPTMF tests under various dwell times
Luft et al. [20] also reported that during the dwell time at the maximum temperature, a distinctive stress relaxation could be observed. This resulted in a decrease of the compressive stress by about $15 \mathrm{MPa}$ at all maximum temperatures for the A356.0-T6 alloy [20].

During the dwell time, slow creep and stress relaxation phenomena take place due to a very low plastic strain rate [35]. The strain rate is in the order of 10-4 per sec. in TMF tests. This stress relaxation is illustrated in Figure 16 for each dwell time at mid-life cycles. In this figure, stress histories versus the time cycle can be observed in OP-TMF tests. The measured value of the stress relaxation is about 15 to $20 \mathrm{MPa}$ for all dwell times (shown in Figure 16). Sasaki and Takahashi [36] also reported about $20 \mathrm{MPa}$ stress relaxation for the AC2B-T6 aluminum alloy under 5 to $20 \mathrm{~min}$ of the dwell time. According to their studies, they depicted that the stress relaxation started at about $220^{\circ} \mathrm{C}$ which is about $56 \%$ of the melting point of aluminum alloys. Considering the temperature range between 0.5 and 0.6 of the melting temperature, both diffusion creep and dislocation creep occur. Therefore, the alloy is considered to be softened at this temperature range. At the same time, there is no stress relaxation in the tensile process where the temperature has minimum value [36].

\section{CONCLUSION}

Effects of several parameters on the OP-TMF behavior of the A356.0 alloy are investigated. Following conclusions are drawn from this work.

A. TMF test results demonstrate that by increasing the maximum temperature and the thermo-mechanical loading factor, the fatigue lifetime decreases significantly, as expected. The effect of the maximum temperature on the TMF lifetime of the A356.0 alloy is less pronounced than the influence of the thermo-mechanical loading factor.

B. The dwell time has no significant effect on the TMF life cycle due to an approximate constant stress relaxation but does lead to a TMF lifetime increase.

C. The A356.0 aluminum alloy shows the cyclic softening behavior under OP-TMF conditions where the fracture surface has features of the ductile behavior.

\section{AKNOWLEDGEMENTS}

The authors thank Irankhodro Powertrain Company (IPCO), in Iran for the financial support and also thank University of Leoben, in Austria for their kind cooperation. 


\section{REFERENCES}

1. Yi, J., Lee, P., Lindley, T. and Fukui, T., "Statistical modeling of microstructure and defect population effects on the fatigue performance of cast a356-t6 automotive components", Materials Science and Engineering: A, Vol. 432, No. 1, (2006), 59-68.

2. Moridi, A., Azadi, M. and Farrahi, G., "Coating thickness and roughness effect on stress distribution of a356. 0 under thermomechanical loadings", Procedia Engineering, Vol. 10, (2011), 1372-1377.

3. Moridi, A., Azadi, M. and Farrahi, G., "Thermo-mechanical stress analysis of thermal barrier coating system considering thickness and roughness effects", Surface and Coatings Technology, (2012)

4. McDowell, D., Gall, K., Horstemeyer, M. and Fan, J., "Microstructure-based fatigue modeling of cast a356-t6 alloy", Engineering Fracture Mechanics, Vol. 70, No. 1, (2003), 4980 .

5. Atzori, B., Meneghetti, G. and Susmel, L., "Fatigue behaviour of aa356-t6 cast aluminium alloy weakened by cracks and notches", Engineering Fracture Mechanics, Vol. 71, No. 4, (2004), 759-768.

6. Zhu, X., Shyam, A., Jones, J., Mayer, H., Lasecki, J., and Allison, J., "Effects of microstructure and temperature on fatigue behavior of e319-t7 cast aluminum alloy in very long life cycles", International Journal of Fatigue, Vol. 28, No. 11, (2006), 1566-1571.

7. Gan, Y. X. and Overfelt, R. A., "Fatigue property of semisolid a357 aluminum alloy under different heat treatment conditions", Journal of Materials Science, Vol. 41, No. 22, (2006), $7537-$ 7544

8. Yi, J., Gao, Y., Lee, P. and Lindley, T., "Microstructure-based fatigue life prediction for cast a356-t6 aluminum-silicon alloys", Metallurgical and Materials Transactions B, Vol. 37, No. 2, (2006), 301-311.

9. McDowell, D. L., "Simulation-based strategies for microstructure-sensitive fatigue modeling", Materials Science and Engineering: A, Vol. 468, (2007), 4-14

10. Ammar, H., Samuel, A. and Samuel, F., "Porosity and the fatigue behavior of hypoeutectic and hypereutectic aluminumsilicon casting alloys", International Journal of Fatigue, Vol. 30, No. 6, (2008), 1024-1035

11. Bayoumi, M., Negm, M. and El-Gohry, A., "Microstructure and mechanical properties of extruded al-si alloy (a356) in the semisolid state", Materials \& Design, Vol. 30, No. 10, (2009), 4469. 4477.

12. Mattos, J. J. I., Uehara, A. Y., Sato, M. and Ferreira, I., "Fatigue properties and micro-mechanism of fracture of an alsimg 0.6 cast alloy used in diesel engine cylinder head", Procedia Engineering, Vol. 2, (2010), 759-765.

13. Rohatgi, P., Alaraj, S., Thakkar, R. and Daoud, A., "Variation in fatigue properties of cast a359-sic composites under total strain controlled conditions: Effects of porosity and inclusions", Composites Part A: Applied Science and Manufacturing, Vol. 38, No. 8, (2007), 1829-1841.

14. Emami, A., Begum, S., Chen, D., Skszek, T., Niu, X., Zhang, Y., and Gabbianelli, F., "Cyclic deformation behavior of a cast aluminum alloy", Materials Science and Engineering: A, Vol 516, No. 1, (2009), 31-41.

15. Mousheng, S. and Maowu, R., "Microstructures and properties of low cycle fatigue of electrolytic a356 alloys", Materials Characterization, Vol. 62, No. 4, (2011), 367-372.

16. Takahashi, T., Sugimura, Y. and Sasaki, K., "Thermal plasticelastic analysis in consideration of metallurgical microstructure",
Journal of Manufacturing Science and Engineering, Vol. 126 , No. 1, (2004), 25-32.

17. Smith, T. J., Sehitoglu, H., Fleury, E., Maier, H. J. and Allison, J., "Modeling high-temperature stress-strain behavior of cast aluminum alloys", Metallurgical and Materials Transactions A, Vol. 30, No. 1, (1999), 133-146.

18. Sehitoglu, H., Smith, T., Qing, X., Maier, H. J. and Allison, J., "Stress-strain response of a cast 319-t6 aluminum under thermomechanical loading", Metallurgical and Materials Transactions A, Vol. 31, No. 1, (2000), 139-151.

19. Beck, T., Lang, K.-H. and Lohe, D., "Thermal-mechanical fatigue behaviour of cast aluminium alloys for cylinder heads reinforced with 15 vol.\% discontinuous 2 o 3 (saffil) fibers", International Journal of Materials and Product Technology, Vol. 18, No. 1, (2003), 160-177.

20. Luft, J., Beck, T. and Löhe, D., "3406-lifetime and damage behaviour of a cast aluminium alloy under $\operatorname{tmf}$ and superimposed tmf/hcf loading", in ICF11, Italy 2005. (2013).

21. Beck, T., Löhe, D., Luft, J. and Henne, I., "Damage mechanisms of cast al-si-mg alloys under superimposed thermal-mechanical fatigue and high-cycle fatigue loading", Materials Science and Engineering: A, Vol. 468, (2007), 184-192.

22. Beck, T., Henne, I. and Löhe, D., "Lifetime of cast alsi6cu4 under superimposed thermal-mechanical fatigue and high-cycle fatigue loading", Materials Science and Engineering: A, Vol. 483, (2008), 382-386

23. Thomas, J.-J., Verger, L., Bignonnet, A. and Charkaluk, E., "Thermomechanical design in the automotive industry", Fatigue \& Fracture of Engineering Materials \& Structures, Vol. 27, No. $10,(2004), 887-895$

24. Thomas, J. J., Verger, L., Bignonnet, A. and Borret, S. M., "Thermo-mechanical design in the automotive industry", $\boldsymbol{S A E}$ International, (2002)

25. Bose-Filho, W., de Freitas, E., da Silva, V., Milan, M. and Spinelli, D., "Al-si cast alloys under isothermal and thermomechanical fatigue conditions", International Journal of Fatigue, Vol. 29, No. 9, (2007), 1846-1854.

26. Riedler, M., Czettl, C., Minichmayr, R., Winter, G. and Eichlseder, W., Thermo-mechanical fatigue lifetime assessment with damage-parameters, energy-criteria and cyclic-j-integral concepts, in 16th European Conference of Fracture.: Alexandroupolis, Greece,. (2006)

27. Riedler, M., Leitner, H., Prillhofer, B., Winter, G. and Eichlseder, W., "Lifetime simulation of thermo-mechanically loaded components", Meccanica, Vol. 42, No. 1, (2007), 47-59.

28. Sasaki, K., "Low cycle thermal fatigue of aluminum alloy cylinder head in consideration of changing metrology microstructure", Procedia Engineering, Vol. 2, No. 1, (2010), 767-776.

29. Tabibian, S., Charkaluk, E., Constantinescu, A., Oudin, A. and Szmytka, F., "Behavior, damage and fatigue life assessment of lost foam casting aluminum alloys under thermo-mechanical fatigue conditions", Procedia Engineering, Vol. 2, No. 1, (2010), 1145-1154.

30. Grieb, M. B., Christ, H.-J. and Plege, B., "Thermomechanical fatigue of cast aluminium alloys for cylinder head applicationsexperimental characterization and life prediction", Procedia Engineering, Vol. 2, No. 1, (2010), 1767-1776.

31. Liu, A. F., "Mechanics and mechanisms of fracture: An introduction", ASM International, (2005).

32. Halford, G. R., "Fatigue and durability of structural materials", ASM International, (2006).

33. Shankar, V., Bauer, V., Sandhya, R., Mathew, M. and Christ, H.-J., "Low cycle fatigue and thermo-mechanical fatigue behavior of modified $9 \mathrm{cr}-1 \mathrm{mo}$ ferritic steel at elevated 
temperatures", Journal of Nuclear Materials, Vol. 420, No. 1, (2012), 23-30.

34. Zhang, X. Z., Ahmmed, K., Wang, M. and Hu, H., "Influence of aging temperatures and times on mechanical properties of vacuum high pressure die cast aluminum alloy a356", Advanced Materials Research, Vol. 445, No., (2012), 277-282.
35. Lemaitre, J. and Desmorat, R., "Engineering damage mechanics: Ductile, creep, fatigue and brittle failures", Springer, (2005).

36. Sasaki, K. and Takahashi, T., "Low cycle thermal fatigue and microstructural change of ac2b-t6 aluminum alloy", International Journal of Fatigue, Vol. 28, No. 3, (2006), 203210

\title{
The Effect of Various Parameters on Out-of-phase Thermo-mechanical Fatigue Lifetime of A356.0 Cast Aluminum Alloy
}

\author{
M. Azadi a,b, G. H. Farrahi a, G. Winter c, W. Eichlseder c
}

${ }^{a}$ School of Mechanical Engineering, Sharif University of Technology, Tehran, Iran

${ }^{b}$ Fatigue and Wear Workgroup, Irankhodro Powertrain Company (IPCO), Tehran, Iran

${ }^{c}$ Chair of Mechanical Engineering, University of Leoben, Leoben, Austria

\section{PAPER INFO}

\section{Paper history:}

Received 14 March 2013

Received in revised form 10 May 2013

Accepted 16 May 2013

\section{Keywords:}

Thermo-mechanical Fatigue

A356.0 Aluminum Alloy

Dwell Time

Maximum Temperature

Cyclic Softening

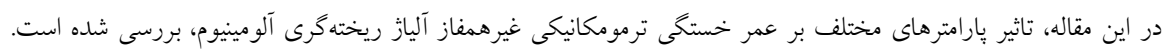

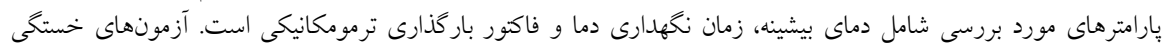

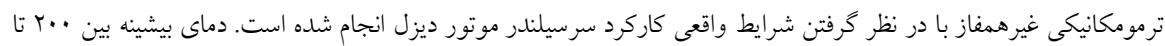

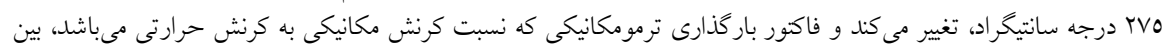

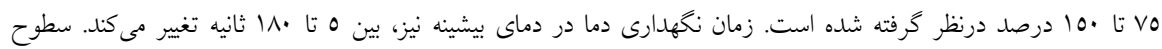

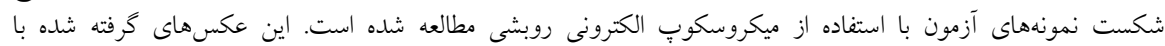

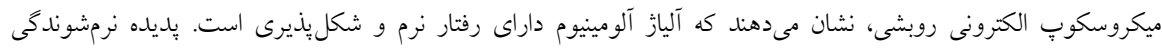

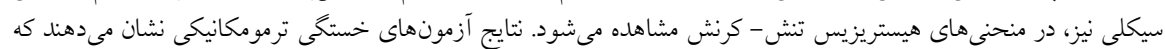

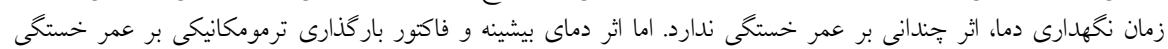

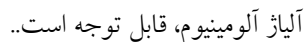




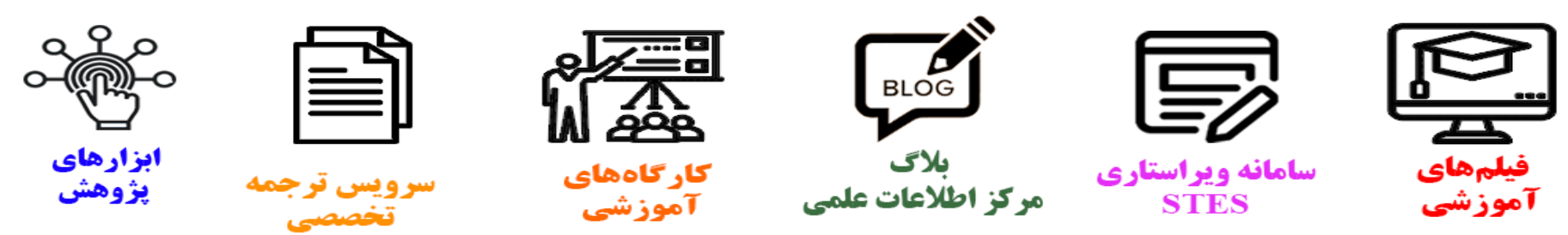

\section{(c)}

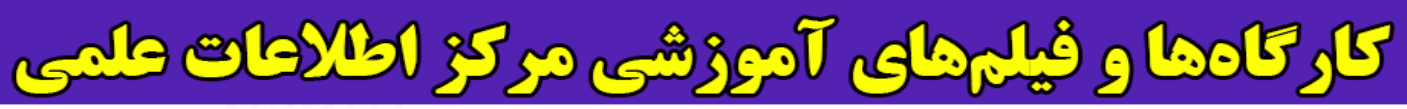
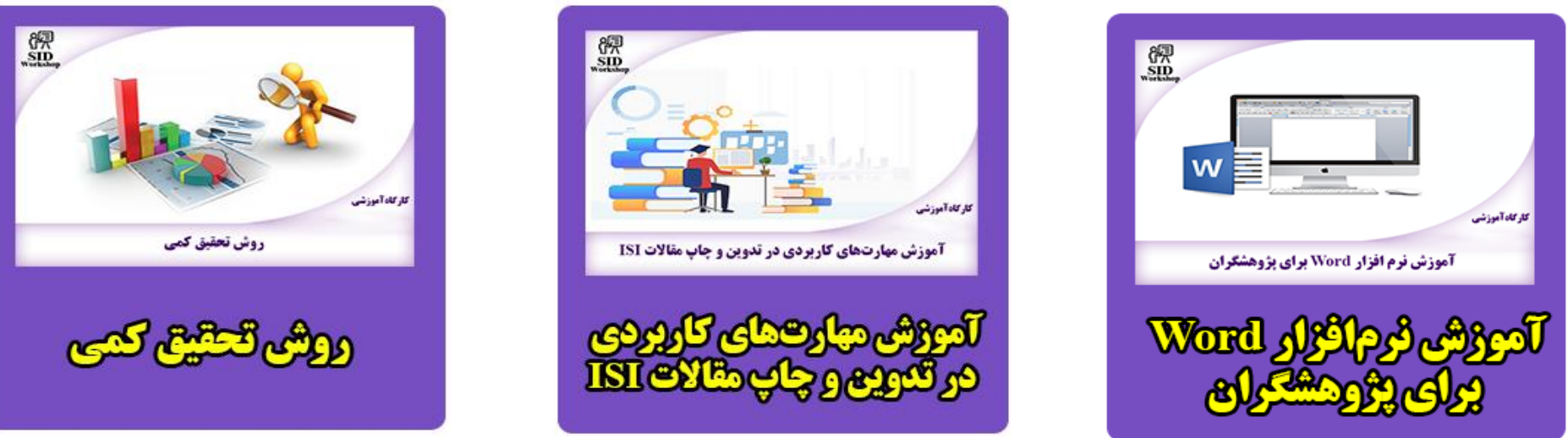